\title{
Human Cytomegalovirus-Induced Degradation of CYTIP Modulates Dendritic Cell Adhesion and Migration
}

\author{
Linda Grosche ${ }^{1}$, Christina Draßner', Petra Mühl-Zürbes ', Lisa Kamm', \\ Vu Thuy Khanh Le-Trilling ${ }^{2}$, Mirko Trilling ${ }^{2}$, Alexander Steinkasserer ${ }^{1}$ \\ and Christiane S. Heilingloh ${ }^{1 *}$
}

\begin{abstract}
'Department of Immunomodulation, University Hospital Erlangen, Erlangen, Germany, ${ }^{2}$ Institute for Virology, University
\end{abstract} Hospital Essen, Essen, Germany

\section{OPEN ACCESS}

Edited by:

Hubertus Hochrein, Bavarian Nordic, Germany

Reviewed by: Mark R. Wills, University of Cambridge, UK Yan Shi,

Tsinghua University, China

${ }^{*}$ Correspondence:

Christiane S. Heilingloh christiane.heilingloh@uk-erlangen.de

Specialty section: This article was submitted to Antigen Presenting Cell Biology, a section of the journal Frontiers in Immunology

Received: 10 January 2017 Accepted: 04 April 2017 Published: 21 April 2017

Citation: Grosche L, Draßner C, Mühl-Zürbes P, Kamm L, Le-Trilling VTK, Trilling $M$, Steinkasserer $A$ and Heilingloh CS (2017) Human Cytomegalovirus-

Induced Degradation of CYTIP Modulates Dendritic Cell Adhesion and Migration.

Front. Immunol. 8:461. doi: 10.3389/fimmu.2017.00461
As potent antigen-presenting cells, dendritic cells (DCs) are essential for the initiation of effective antiviral immune responses. Viruses and especially herpesviruses, which are able to establish lifelong persistence, exploit several immune evasion mechanisms targeting DC biology. Our group has previously shown that the $\alpha$-herpesvirus herpes simplex virus type 1 inhibits mature $\mathrm{DC}(\mathrm{mDC})$ migration by inducing adhesion via degrading the cellular protein CYTIP (cytohesin-1 interacting protein), an important negative regulator of $\beta 2$-integrin activity. In the present study, we extended our analysis to the $\beta$-herpesvirus human cytomegalovirus (HCMV), to investigate whether other herpesviridae also induce such modulations. Indeed, HCMV impairs mDC transwell migration capability following a CCL19-chemokine gradient, despite equivalent expression levels of the cognate chemokine receptor CCR7 at the corresponding time points post-infection. Remarkably, HCMV infection potently induced $\beta 2$-integrin activity on mDCs. Furthermore, directly HCMV-infected mDCs, exhibiting viral gene expression, strongly adhere to fibronectin and ICAM-1, in contrast to mDCs lacking infection or viral gene expression. Interestingly, HCMV-positive mDCs display a proteasome-dependent degradation of CYTIP. Contrasting the migration toward CCL19, elevated expression levels of the chemokine receptor CXCR4 in HCMV-infected mDCs were associated with functional CXCL12chemotaxis under the herein used conditions. In summary, our results show that HCMV shapes mDC adhesion to compromise migration toward CCL19, but retaining CXCL12 responsiveness. Thus, we hypothesize that a preferred migration pattern toward the bone marrow, but not to secondary lymphoid organs, could ultimately cause a failure in the induction of potent antiviral immune responses.

Keywords: dendritic cells, HCMV, CYTIP, proteasomal degradation, adhesion, migration

\section{INTRODUCTION}

Dendritic cells (DCs) are very potent antigen-presenting cells operating at the interface of innate and adaptive immunity specialized for activation of lymphocytes, especially naïve T-cells (1-3). Importantly, DCs reside immobilized in an immature state in peripheral tissues (4) until maturation is induced by stimulation via pattern recognition receptors, antigen uptake, or specific 
pro-inflammatory cytokines (5). These maturing DCs upregulate the expression of MHC I and II as well as of costimulatory molecules (6). Furthermore, the chemokine receptors CCR7 and CXCR4 are highly expressed on mature DCs (mDCs) (7-10). CXCR4 binds the widely expressed chemokine CXCL12 (SDF-1), homing the cell, e.g., to the bone marrow where the highest expression is found $(11,12)$. In contrast, CCR7 responds to the chemokines CCL19 and CCL21, highly expressed in secondary lymphoid organs (SLOs), directing mDCs to SLOs for $\mathrm{T}$ cell activation $(13,14)$.

Leukocytes and especially DCs are very motile cells circulating through different tissues and lymphoid organs. In general, migration requires multiple changes in cytoskeleton architecture and cell-substrate interactions (15), regulated, e.g., by chemokine perception and signaling with rearrangement of the cytoskeleton and modulation of adhesion (16-18). Integrins are heterodimeric transmembrane receptors that mediate adhesion and comprise a very high diversity by the combination of $\alpha$ - and $\beta$-chains resulting in 24 members in mammalia, all possessing different ligands and binding affinities (19). Leukocytes express integrins of the $\beta 1-, \beta 2-, \beta 3$ - and $\beta 7$-families, while $\beta 2$ - and $\beta 7$-integrins are restricted to these cells (20). The $\beta 2$-integrins consist of the $\beta$-subunit cluster of differentiation (CD) 18 that associates with one of the four different $\alpha$-chains to form LFA-1 (CD11a/CD18 or $\alpha \mathrm{L} \beta 2$ ), Mac-1 or CR3 (CD11b/CD18 or $\alpha \mathrm{M} \beta 2)$, p150.95 (CD11c/CD18 or $\alpha \mathrm{X} \beta 2)$ and $\alpha \mathrm{D} \beta 2$ (CD11d/ CD18) (21, 22). Expression of the latter ones is restricted to specific leukocyte subsets, while LFA-1 is constitutively expressed on all leukocytes, thus playing essential roles in controlling adhesion and cellular interactions (21, 23-25). Like all other integrins, LFA-1 dynamically switches between its active and inactive conformation, mediated by outside-in and inside-out signaling $(19,26)$. Only two proteins talin and cytohesin-1 are currently known to modulate LFA-1 activity by direct binding to its cytoplasmic CD18 tail (27). Interestingly, the latter one was reported to be specific for $\beta 2$-integrins and to be predominantly expressed in hematopoietic cells $(28,29)$. Cytohesin- 1 interacting protein (CYTIP), a direct interactor of cytohesin-1, is expressed by hematopoietic cells and upregulated during DC maturation (30-32). One important function of CYTIP is to abrogate cytohesin-1-induced activation of LFA-1. Cytohesin-1 directly interacts with membrane associated phosphatidylinositol-3,4,5trisphosphate (PIP3), produced by phosphoinositide 3-kinase (33), and the intracellular CD18 domain of LFA-1 resulting in increased LFA-1 affinity, promoting adhesion to its ligands $(28,29,34)$. CYTIP reverses these interactions by binding to cytohesin-1, with subsequent translocation of the cytohesin-1/ CYTIP-complex to the cytosol, thereby diminishing LFA-1 affinity and ultimately adhesion (30).

The $\beta$-herpesvirus human cytomegalovirus (HCMV) exhibits seroprevalences of $45 \%$ up to almost $100 \%$ depending on age, gender and socioeconomic situation (35). While the primary infection of healthy adult individuals is usually subclinical, infections of immune-immature fetus or neonates as well as immunocompromised patients frequently leads to severe symptoms with high morbidity and mortality (36). Permissive target cells for HCMV replication are fibroblasts, smooth muscle cells, epithelial cells, and endothelial cells $(37,38)$. Apart from the productive lytic replication, herpesviruses establish lifelong latency in the host, despite the presence of an immune response. Regarding HCMV, CD34 ${ }^{+}$hematopoietic progenitor cells (39-41) and $\mathrm{CD}_{14}{ }^{+}$monocytes $(42,43)$ are widely accepted reservoirs for latency.

Since DCs are important stimulators of antiviral immune responses, herpesviruses evolved several strategies to interfere with DC functions. One example is the herpes simplex virus type 1 (HSV-1)-induced inhibition of $\mathrm{mDC}$ migration. This is mediated via the downregulation of CCR7 and CXCR4 surface expression as well as the activation of LFA-1 via the degradation of CYTIP leading to significantly induced adhesion of mDCs $(44,45)$. However, it was unknown whether this represents a unique immune evasion mechanism of HSV-1 or if other members of the herpesviridae family including HCMV also regulate $\mathrm{mDC}$ adhesion and migration, which would imply an analogous or even evolutionary conserved immune evasion mechanism.

In the present study, we provide evidence that HCMV modulates $\mathrm{mDC}$ adhesion and migration. We show a differential regulation of CCR7 and CXCR4 upon HCMV infection of mDCs. Moreover, HCMV induces activation of $\beta 2$-integrins via proteasomal degradation of CYTIP in mDCs in which HCMV established viral gene expression. This leads to increased adhesion of infected mDCs to ICAM-1 and fibronectin, which in turn influences the $\mathrm{mDC}$ migration capability. Hence, we suggest that this immune evasion mechanism has been evolved by at least one prototypic member of the $\alpha$ - as well as $\beta$-herpesviridae family, to hamper the induction of potent antiviral immune responses.

\section{MATERIALS AND METHODS}

\section{Generation of DCs}

Mature DCs were generated from peripheral blood mononuclear cells (PBMCs) from healthy donors as reported earlier (46). PBMCs were isolated by sedimentation with Lymphoprep (Nycomed Pharma) as previously described (47). Cells were cultured in DC medium (RPMI 1640 medium [BioWhittaker] supplemented with $100 \mathrm{U}$ penicillin $\mathrm{ml}^{-1}, 100 \mathrm{mg}$ streptomycin $\mathrm{ml}^{-1}$ [Sigma], $1 \%(\mathrm{v} / \mathrm{v})$ autologous serum, $2 \mathrm{mM} \mathrm{L-glutamine}$ [Cambrex BioScience] and $10 \mathrm{mM}$ HEPES pH 7.5 [SigmaAldrich]) and were allowed to adhere on standard tissue flasks (Nunc) for $1 \mathrm{~h}$. Subsequently, non-adherent cells were rinsed off with RPMI, and differentiation to DCs was performed as described elsewhere (48). Briefly, iDCs were generated by addition of $800 \mathrm{U}$ of granulocyte-macrophage colony-stimulating factor (GM-CSF) $\mathrm{ml}^{-1}$ (Miltenyi) and $250 \mathrm{U} \mathrm{IL}-4 \mathrm{ml}^{-1}$ (Miltenyi) in DC medium. Maturation of DCs was induced by adding $40 \mathrm{U}$ GM-CSF ml ${ }^{-1}, 250$ U IL-4 ml-1 10 ng TNF- $\alpha \mathrm{ml}^{-1}$ (Peprotech), $1 \mathrm{mg}$ prostaglandin E2 $\mathrm{ml}^{-1}$ (Pfizer), $200 \mathrm{U} \mathrm{IL}-1 \beta \mathrm{ml}^{-1}$ (CellGenix) and 1,000 U IL-6 $\mathrm{ml}^{-1}$ (Cell-Genix) to the medium. After 2 days, DC maturation status was analyzed by flow cytometry.

\section{Cells and Viruses}

The HSV-1/17+/CMV-EGFP/UL43 strain, used in this study, contains the EGFP reporter cassette under control of the CMV 
promoter inserted into the UL43 locus of HSV-1 strain $17+$. Virus stock preparation and titer determination were performed as described previously (49). The HSV-1 strain was obtained from BioVex.

For HCMV infection, the HCMV TB40E/IE2-EYFP strain (50) expressing IE2-EYFP fusion protein (kindly provided by Thomas Stamminger, Institute for Clinical and Molecular Virology, Erlangen) or HCMV-TB40E-green fluorescence protein (GFP) was used. HCMV stocks were prepared on ARPE-19 cells, followed by propagation on human fibroblasts (HFF or MRC-5 cells), cultured in Dulbecco's Modified Eagel's Medium (DMEM; Lonza) supplemented with 10\% (v/v) FCS (PAA), 2 mM

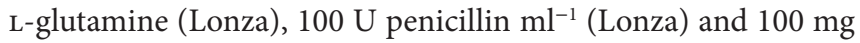
streptomycin $\mathrm{ml}^{-1}$ (Lonza). Virus-containing supernatants were harvested when all cells showed cytopathic effects. Remaining adherent cells were scraped from the flask and added to the supernatant. Cellular debris as well as intact cells were collected by centrifugation and homogenized using a tissue grinder (VWR) to release intracellular virions. Cellular debris in the virus suspensions were finally removed by centrifugation, and virus-containing supernatant was stored at $-80^{\circ} \mathrm{C}$. Titration of the respective HCMV strains was carried out as described elsewhere (51). Ultraviolet (UV)-inactivated virus (HCMV-UV) was generated by irradiation of $\mathrm{HCMV}$-containing suspensions with defined doses of UV light $\left(1,200 \mathrm{~J} / \mathrm{cm}^{2}\right)$.

\section{HSV-1 Infection of mDCs}

Mature DCs were harvested and washed in PBS. Cells $\left(1 \times 10^{6}\right)$ were resuspended in $300 \mu \mathrm{l}$ RPMI 1640 (Lonza) supplemented with $20 \mathrm{mM}$ HEPES (N-2-hydroxyethylpiperazine- $N$-2ethanesulfonic acid, Lonza). Cells were then incubated with HSV-1 at a multiplicity of infection (MOI) of 2 for $1 \mathrm{~h}$ at $37^{\circ} \mathrm{C}$ and shaking at $300 \mathrm{rpm}$. After collecting the cells by centrifugation, they were cultured in DC medium supplemented with $40 \mathrm{U}$ GM-CSF ml-1 and $250 \mathrm{U} \mathrm{IL}-4 \mathrm{ml}^{-1}$ until further use. For proteasomal inhibition, $10 \mu \mathrm{M}$ of MG-132 (Enzo Life Science) or dimethyl sulfoxide (Sigma-Aldrich) as control was added 1 hour post-infection (hpi).

\section{HCMV Infection of mDCs}

Mature DCs were collected and washed once in PBS. Cells $\left(5 \times 10^{5}\right)$ were resuspended in the respective volume of HCMV virus stock at an MOI of 3 . For mock condition, mDCs were resuspended in the respective volume of DMEM supplemented with $10 \%$ FCS, $2 \mathrm{mM}$ L-glutamine, $100 \mathrm{U}$ penicillin $\mathrm{ml}^{-1}$ and $100 \mathrm{mg}$ streptomycin $\mathrm{ml}^{-1}$. For infection, $\mathrm{mDC}$ s were centrifuged at $1,500 \times g$ at room temperature for $1 \mathrm{~h}$. Afterward, cells were cultured in DC medium containing $40 \mathrm{U} \mathrm{GM}-\mathrm{CSF} \mathrm{ml}^{-1}$ and $250 \mathrm{U} \mathrm{IL}-4 \mathrm{ml}^{-1}$ in a final volume of $1 \mathrm{ml}$.

\section{Mg/EGTA Treatment of mDCs}

For induction of integrin activity, mDCs were treated as described previously (52). Briefly, cells were resuspended in RPMI 1640 supplemented with $20 \mathrm{mM}$ HEPES, $5 \mathrm{mM} \mathrm{MgCl}_{2}$ and $1 \mathrm{mM}$ ethylene glycol-bis( $\beta$-aminoethyl ether)- $N, N, N^{\prime}, N^{\prime}$-tetraacetic acid (EGTA). After 30 -min incubation at $37^{\circ} \mathrm{C}$, cells were subjected to flow cytometric analyses, fibronectin adhesion, or transwell migration assay.

\section{Flow Cytometric Analyses, Fluorescence- Activated Cell Sorting (FACS) and Antibodies Used}

To verify purity and maturation status of DCs, flow cytometric analyses were performed. For HCMV infection experiments, surface expression of different surface proteins was analyzed by staining with the following labeled monoclonal antibodies: CCR7-PE/Cy7 (clone G043H7, BioLegend), CXCR4-APC (clone 12G5, BioLegend), CD11a-PE (clone TS2/4, BioLegend), CD11b-APC-Cy7 (clone ICRF44, BD Biosciences), CD11cPeCy5 (clone B-ly6, BD Biosciences), CD18-APC (clone CBR LFA-1/2, BioLegend), anti-activated CD11/CD18 clone mAB24 (Hycult Biotech), or the isotype control mouse IgG1 $\kappa$ (clone P3.6.2.8.1, eBiosciences) with subsequent incubation with an AlexaFluor647-labeled secondary antibody (Invitrogen). Indicated antibodies were resuspended in PBS supplemented with $2 \%(\mathrm{v} / \mathrm{v})$ FCS. Intracellular flow cytometry analyses for detection of CYTIP and cytohesin-1 (using the mAbs rat antiCYTIP clone 2F9 and rat anti-cytohesin-1 clone 7H2, respectively; kind gift from E. Kremmer, Helmholtz Center Munich, Germany) were performed using Cytofix/Cytoperm kit (BD Biosciences) according to the manufacturer's instructions, with subsequent incubation with a PE-labeled secondary antibody (clone Poly4054, BD Biosciences). For life/dead discrimination, the cells were additionally stained using the LIVE/DEAD Fixable Violet dead cell stain kit (Life Technologies). Staining procedures were performed at $4^{\circ} \mathrm{C}$ and prior to flow cytometry analyses cells were fixed in PBS supplemented with 2\% (v/v) FCS and $2 \%(\mathrm{w} / \mathrm{v})$ PFA (Alfa Aeasar). Gating on HCMV-positive or negative $\mathrm{mDC}$ was based on their GFP/YFP signal. Flow cytometric measurements were performed using a BD FACS Canto II (BD Biosciences), and data were analyzed using FCS express 5. FACS for HCMV-positive or -negative mDCs was performed using a BD Aria FACS cell sorter (BD Biosciences).

\section{Western Blot Analyses and Antibodies Used}

Cell lysates were prepared with NP-40 lysis buffer $(10 \%[\mathrm{v} / \mathrm{v}]$ glycerol; 2 mM EDTA, pH 8; 137 mM NaCl; 50 mM Tris pH 7.2; $0.5 \%$ [v/v] NP-40) supplemented with $20 \mathrm{mM}$ sodium fluoride, $2 \mathrm{mM}$ phenylmethanesulfonyl fluoride, and $2 \mathrm{mM}$ sodium orthovanadate. After incubation for $20 \mathrm{~min}$ on ice, lysates were cleared by centrifugation at $15,900 \times g$ for $20 \mathrm{~min}$ at $4^{\circ} \mathrm{C}$. Subsequently, $4 \times$ Laemmli buffer (125 mM Tris- $\mathrm{HCl} \mathrm{pH} \mathrm{6.8,4 \%} \mathrm{SDS,} 20 \%$ [v/v] glycerin, bromophenol blue, 10\% [v/v] 2-mercaptoethanol) was added, and samples were boiled at $95^{\circ} \mathrm{C}$ for $5 \mathrm{~min}$. After separating the proteins by SDS-PAGE, Western blotting on a nitrocellulose membrane (GE Healthcare) was performed. Membranes were blocked with $1 \times$ RotiBlock (CarlRoth) and incubated with the indicated primary antibodies in $1 \times$ RotiBlock at $4^{\circ} \mathrm{C}$ overnight. The following primary antibodies were used: CYTIP and cytohesin-1 (mAbs rat anti-CYTIP clone 2F9 and rat anti-cytohesin-1 clone 7H2, respectively), anti-IE2 (clone 12E2, 
Santa Cruz Biotechnology), anti-ICP0 (clone 11060, Santa Cruz Biotechnology), and anti-GAPDH (clone 6C5, Millipore). After incubation with the appropriate secondary HRP-labeled antibody (Cell Signaling Technology) for $1 \mathrm{~h}$ at room temperature, signals were detected using Amersham ECL Prime Western Blotting Detection Reagent (GE Healthcare).

\section{Fibronectin Adhesion Assay}

Fibronectin coating of 96-well Maxisorp plates (Nunc) was performed using $20 \mu \mathrm{g}$ fibronectin $\mathrm{ml}^{-1}$ (Sigma-Aldrich) in PBS with incubation at $4^{\circ} \mathrm{C}$ overnight. Subsequently, wells were blocked with $0.01 \%(w / v)$ gelatin (Sigma-Aldrich) in PBS for $2 \mathrm{~h}$ at room temperature. Directly before adhesion wells were washed in PBS. After harvesting $24 \mathrm{hpi}, \mathrm{mDCs}$ were washed once in PBS and adjusted to $4 \times 10^{5}$ cells per $\mathrm{ml}$ in RPMI 1640 . Per well, $100 \mu \mathrm{l}$ of the DC suspension was added, and cells were allowed to adhere for $45 \mathrm{~min}$ at $37^{\circ} \mathrm{C}$. Subsequently, supernatant was removed, and non-adherent $\mathrm{mDCs}$ were washed off with RPMI 1640. Adherent fraction was rinsed with PBS and fixed with $2 \%(\mathrm{w} / \mathrm{v})$ PFA. To determine input conditions the respective volume of the cell suspension was preserved before initiation of the adhesion assay. Each experimental condition was performed with a total cell number of $2 \times 10^{5}$ cells. Infection rates before and after adhesion were determined using flow cytometry. To calculate the number of adherent cells, their $\beta$-glucuronidase activity was measured as described previously (44). Briefly, cells were resuspended in $25 \mu \mathrm{l}$ PBS and $5 \mu \mathrm{l} 1 \%$ TritonX-100 in PBS was added. After 20-min incubation at room temperature, cell debris was removed by centrifugation at $18,400 \times g$ for $1 \mathrm{~min}$, and lysates were incubated for $6 \mathrm{~h}$ at $37^{\circ} \mathrm{C}$ with $75 \mu \mathrm{l} 10 \mathrm{mM} 4$-nitrophenyl- $\beta$-D-glucuronide (Sigma-Aldrich) solved in $100 \mathrm{mM}$ sodium acetate, $\mathrm{pH} 4$. Subsequently, $100 \mu \mathrm{l} \mathrm{0.4} \mathrm{M} \mathrm{glycine,} \mathrm{pH} 10$, was added, and the absorbance at $405 \mathrm{~nm}$ was measured using a Victor ${ }^{2}$ multilabel counter (PerkinElmer, Jugesheim, Germany). The number of adherent cells was calculated via a separate standard curve for each sample using cells of the input condition.

\section{ICAM Adhesion Assay}

For ICAM-1 coating of 96-well Maxisorp plates (Nunc), wells were coated with $4 \mu \mathrm{g}$ goat anti-human IgG (Fc specific) per ml (Jackson ImmunoResearch Laboratories) in PBS at $4^{\circ} \mathrm{C}$ overnight. After blocking with $1 \%(\mathrm{w} / \mathrm{v}) \mathrm{BSA}$ in $\mathrm{PBS}$ at $37^{\circ} \mathrm{C}$ for 30-min, wells were washed with PBS and subsequently incubated with 500 ng ICAM-1-Fc ml-1 in PBS for $1 \mathrm{~h}$ at $37^{\circ} \mathrm{C}$. Adhesion of $\mathrm{mDCs}$ and quantification of infection rates were performed as described above for the fibronectin adhesion assay.

\section{Transwell Migration Assay}

Membranes of transwell inserts with a pore size of $5 \mu \mathrm{m}$ (Corning Costar) were coated with $20 \mu \mathrm{g}$ fibronectin $\mathrm{ml}^{-1}$ at $4^{\circ} \mathrm{C}$ overnight. Transwell migration assays were performed as described elsewhere (44). In brief, mDCs were harvested $24 \mathrm{hpi}$, washed once in PBS and adjusted to $2 \times 10^{6}$ cells per $\mathrm{ml}$ in DC medium. To eliminate cell clusters, cells were passed with a syringe three times through a 20 gage needle. Transwell inserts were equilibrated with $100 \mu \mathrm{l}$ DC medium, while $600 \mu \mathrm{l}$ of medium was added to the wells of a 24 -well plate. For migration assay, $2 \times 10^{5}$ cells were seeded into the inserts and allowed to migrate at $37^{\circ} \mathrm{C}$ for $2 \mathrm{~h}$ toward chemokine gradients of CCL19 or CXCL12 (100 ng ml-1, TebuBio $\mathrm{GmbH}$ ), added to the lower compartment. Additionally, the respective amount of cells was preserved as starting condition. Afterward, migrated DCs were harvested from the lower chamber. Cell numbers and infection rates before and after migration were determined using flow cytometry.

\section{Immunofluorescence Confocal Microscopy}

Mock- or HCMV-infected mDCs were allowed to adhere on poly-L-lysin (Sigma-Aldrich)-coated glass cover slips. Cells were fixed using $4 \%$ paraformaldehyde and subsequently permeabilized using $0.2 \%$ Triton-X-100. Blocking was performed with $1 \%$ BSA in PBS. Antibodies used for immunofluorescence staining were $\mathrm{mAbs}$ rat anti-CYTIP clone $2 \mathrm{~F} 9$ and rat anti-cytohesin-1 clone $7 \mathrm{H} 2$ and anti-rat AlexaFluor555-conjugated secondary antibody (Invitrogen, Carlsbad, CA, USA). For mounting and additional nuclear staining, Roti $^{\circledR}$-Mount FluorCare DAPI (Carl Roth) was used. Confocal microscopy was performed using a LSM780 microscope (Zeiss, Oberkochen, Germany).

\section{Statistical Analysis}

For determination of significance, data sets of two conditions were analyzed using two-tailed Student's $t$-test. For multiple data sets, one-way analysis of variance was applied. Results are displayed as mean \pm SD. Significance was accepted for $p$-values less than 0.05. ${ }^{* * *}$ indicates $p \leq 0.0001{ }^{* * *} p \leq 0.001{ }^{* *} p \leq 0.01$; ${ }^{*} p \leq 0.05$; and ns, not significant.

\section{RESULTS}

\section{HCMV Reduces mDC Transwell Migration toward CCL19, but Not CXCL12}

As migration of DCs to SLOs is pivotal for induction of immune responses by activation of naïve T cells, DCs constitute potential targets for viral immune evasion strategies. Previously, we showed that HSV-1 efficiently infects monocyte-derived mDCs and inhibits transwell migration toward the SLO-expressed chemokines CCL19 and CXCL12 (44). In order to investigate whether this modulation of migration is a unique mechanism of HSV-1 or also exist in other herpesviridae, we analyzed the influence of HCMV, which represents the prototype of the $\beta$-herpesvirus family.

For all infection experiments performed in the present study, the endotheliotropic strain HCMV-TB40E expressing GFP or an IE2-EYFP (enhanced yellow fluorescent protein) fusion protein was used. The use of the GFP/YFP-tagged HCMV-TB40E strain allows the discrimination of $\mathrm{HCMV}$-positive mDCs that express viral-encoded genes and HCMV-negative mDCs, which were exposed to viral particles and antigens but did not express HCMV-encoded genes. Figure 1A shows a time course analysis of HCMV-infected monocyte-derived mDCs. At the indicated time points, cells were analyzed via flow cytometry for GFP/YFP fluorescence, and approximately $15 \%$ of $\mathrm{mDC}$ expressed EGFP as undeniable indicator of $\mathrm{HCMV}$-induced gene expression $24 \mathrm{hpi}$, with increasing percentages at later time points (Figure 1A). 
A mock HCMV
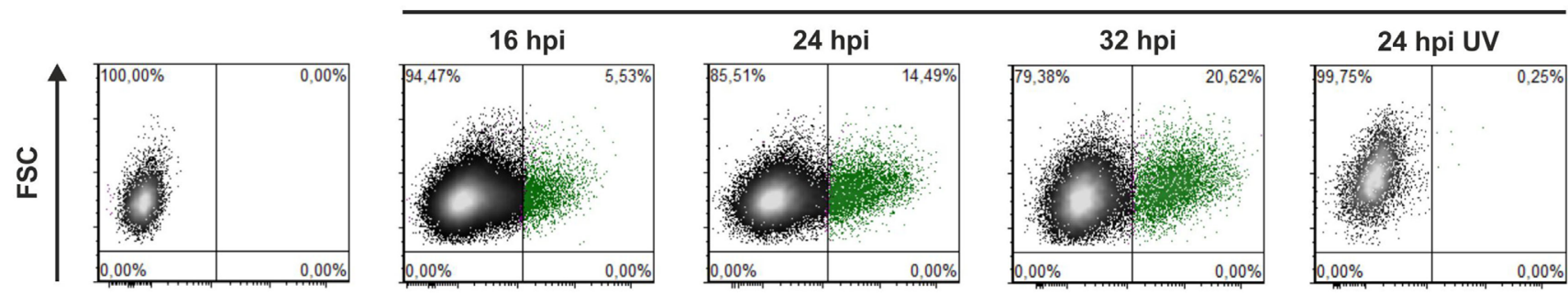

GFP

B

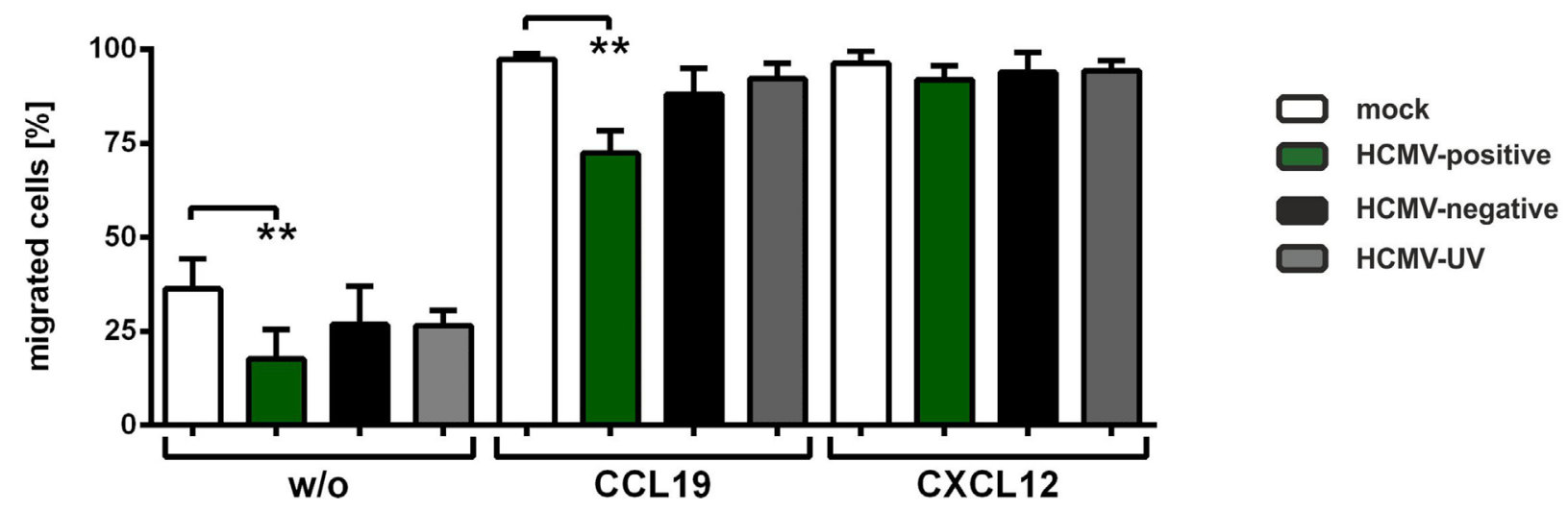

FIGURE 1 | Human cytomegalovirus (HCMV)-infected mature DCs (mDCs) show decreased transwell migration toward CCL19. (A) Mature dendritic cells were mock-, HCMV- or HCMV-ultraviolet (UV)-infected and analyzed for infection rates at the indicated time points. Mock or HCMV/green fluorescence protein (GFP)-negative mDCs are indicated as black dots, while HCMV/GFP-positive cells are marked in green. (B). Mock- (white columns), HCMV-infected mDCs (HCMV-positive cells are depicted in green and HCMV-negative cells in black columns), and HCMV-UV-infected mDCs (gray columns) were subjected to a transwell migration assay on fibronectin-coated transwell inserts $24 \mathrm{hpi}$. To induce chemotaxis the chemokines CCL19 or CXCL12 (100 ng/ml) were added to the lower wells. As control no chemokine was added for spontaneous migration, indicated as "w/O." Migration was evaluated after $2 \mathrm{~h}$, and the percentage of migrated mDCs was calculated in the lower well by determining cell number and infection rates of migrated cells in relation to the respective starting condition. The experiment was performed at least three times with cells from different healthy donors. Significant changes (** $=p<0.01$ ) are indicated by asterisks.

Furthermore, mDCs were infected with UV-inactivated HCMV (HCMV-UV) and analyzed 24 hpi to ensure UV-irradiation efficiency.

To assess the influence of HCMV on mDC chemotaxis, we subjected mock-, HCMV- or HCMV-UV-infected mDCs 24 hpi to transwell migration assays using fibronectin-coated polycarbonate membranes (Figure 1B). After $2 \mathrm{~h}$ of migration without chemokine as well as toward CCL19 or CXCL12, cells in the lower well were counted and infection efficiency was determined before and after migration. No change in CXCL12-mediated chemotaxis was observed comparing mock- (white bar), HCMVpositive (green bar), HCMV-negative (black bar), and HCMVUV-infected (gray bar) mDCs, indicating that HCMV does not compromise the general ability of $\mathrm{mDCs}$ to migrate to chemotactic gradients. However, spontaneous migration without chemokines (w/o) was significantly inhibited for HCMV-positive mDCs compared to mock condition. Interestingly, we observed a significantly reduced migration capability for HCMV-positive $\mathrm{mDCs}$ in CCL19-induced chemotaxis compared to mock cells, HCMV-negative as well as HCMV-UV-infected mDCs (Figure 1B).

\section{Surface Expression of CCR7 and CXCR4 in HCMV-Infected mDCs Does Not Explain Impaired Migration}

Chemotaxis in a transwell system relies on the expression of the respective receptors on the cell surface. Our group previously reported that HSV-1 induces significant downregulation of surface expression of the receptors CCR7 and CXCR4, which are required to recognize CCL19 and CXCL12, respectively (44). To determine alterations in surface expression of both chemokine receptors on $\mathrm{HCMV}$-infected mDCs, we performed time course experiments, with subsequent flow cytometric analyses (Figure 2). The results of one representative experiment of mock, HCMV-positive, HCMV-negative, and HCMVUV-infected mDCs 24 hpi are shown in Figures 2A,C, while the results of at least three independent experiments in a time kinetic are summarized in Figures 2B,D. We demonstrate that CCR7 surface expression is unaffected until $24 \mathrm{hpi}-$ the time frame in which the transwell assay was conducted-followed by a weak downregulation at later time points only in HCMVpositive mDCs (Figure 2B, left panel). Remarkably, in contrast 


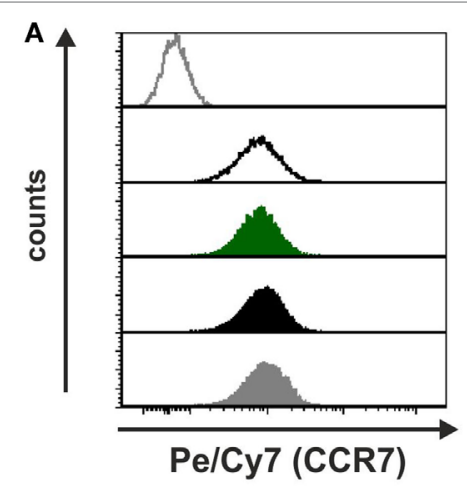

C

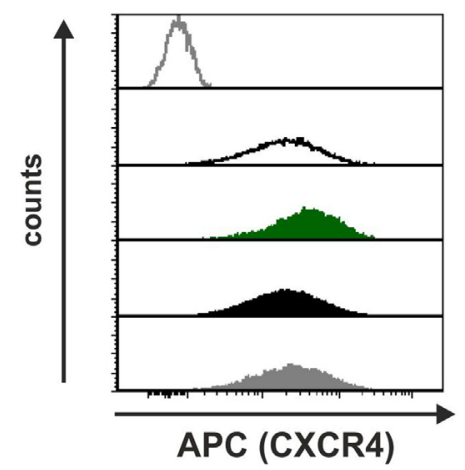

$\mathbf{E}$

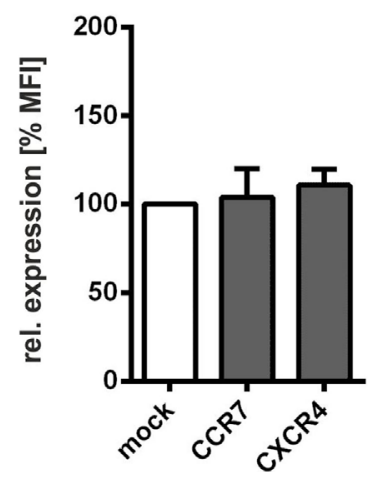

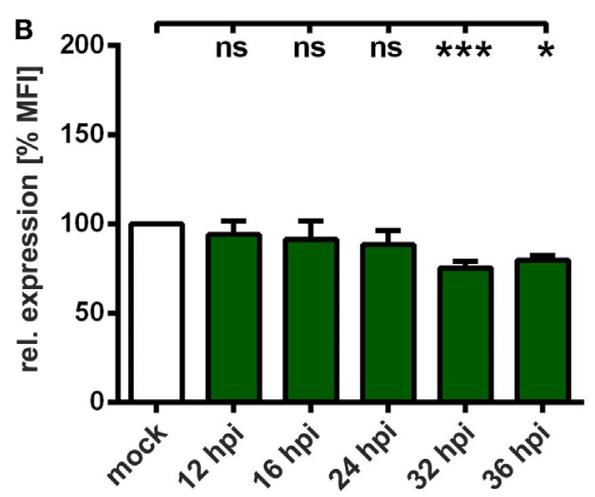

D
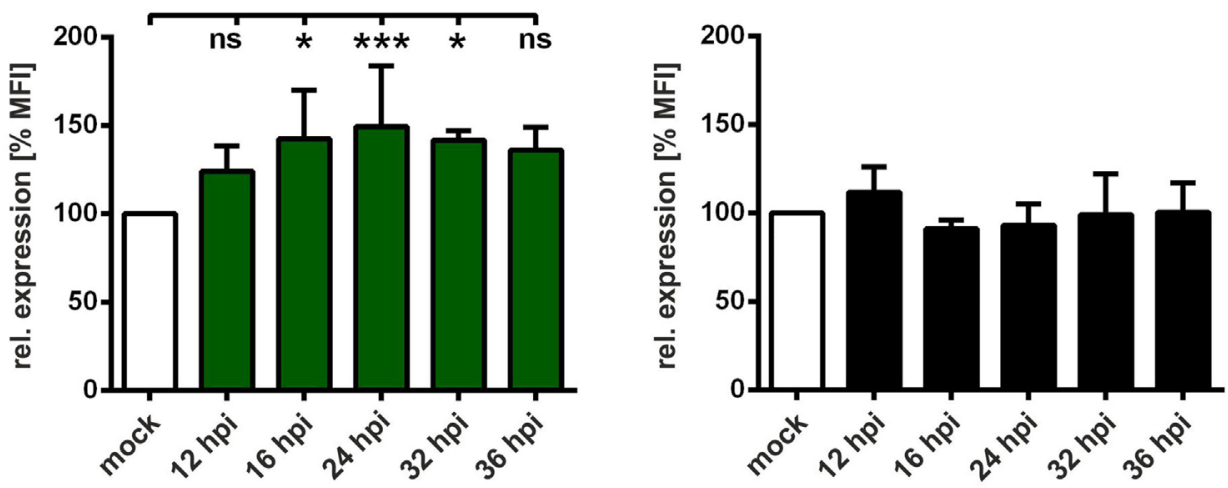

FIGURE 2 | Human cytomegalovirus (HCMV) differentially modulates CCR7 and CXCR4 surface expression on infected mature DCs (mDCs). Mock-, HCMV- or HCMV-ultraviolet (UV)-infected mDCs were harvested at the indicated time points and stained with antibodies specific for CCR7 and CXCR4 for flow cytometric analyses. (A) Representative data of one donor are shown for surface expression of CCR7 and (C) CXCR4 24 hpi. Mock cells (black histogram), HCMV-positive cells (filled green histogram), HCMV-negative cells (filled black histogram), and HCMV-UV-infected cells (filled gray histogram) are depicted. (B) Time kinetics of CCR7 and (D) CXCR4 surface expression are shown as mean fluorescence intensity (MFI) of HCMV-positive (green bars, left panel) and HCMV-negative mDCs (black bars, right panel) relative to mock cells (white bars, set to 100\%). (E) CCR7 and CXCR4 surface expression of HCMV-UV-infected mDCs (gray bars) $24 \mathrm{hpi}$ are shown as MFI relative to mock condition (white bar, set to 100\%). The experiment was performed at least three times with cells from different healthy donors. Significant changes $\left({ }^{\star \star \star}=p<0.001 ;{ }^{*}=p<0.05\right)$ are indicated by asterisks, non-significant changes $(p>0.05)$ as "ns."

to the downregulation of CCR7, HCMV even induced CXCR4 expression already $12 \mathrm{hpi}$, peaking at $24 \mathrm{hpi}$ with an induction of approximately $150 \%$ only observed in HCMV-positive mDCs (Figure 2D, left panel). No changes in CCR7 and CXCR4 surface expression were detected on HCMV-negative (Figures 2B,D, right panels) as well as on HCMV-UV-infected mDCs (Figure 2E).
The surface disposition of these two chemokine receptors was altered on HCMV-positive mDCs but failed to explain their impaired transwell migration observed within the first $24 \mathrm{~h}$ of $\mathrm{mDC}$ infection. Hence, additional mechanism(s), apart from meaningful downregulation of CCR7 surface expression, were considered as cause for the observed inhibition of transwell migration toward CCL19. 


\section{HCMV Induces mDC Adhesion by Increasing $\beta 2$-Integrin Activity Leading to Impaired CCL19-Directed Transwell Migration}

Having demonstrated that HCMV does not downregulate surface expression of CCR7 until $24 \mathrm{hpi}$, we intended to elucidate the mechanism by which migration in this $2 \mathrm{D}$ system is inhibited. Apart from chemokine receptor expression, mDC adhesion on the fibronectin-coated transwell polycarbonate-membrane could be modulated by HCMV to inhibit migration. While fibronectin represents a prototypic ligand for a variety of cell adhesion molecules, belonging to $\beta 1-, \beta 2-, \beta 3$ - and $\beta 7$-integrin families $(53,54)$, ICAM- 1 is a specific ligand for the $\beta 2$-integrins LFA- 1 and Mac-1 (55).

Therefore, we next analyzed adhesion of HCMV-infected mDCs on ICAM-1 or fibronectin-coated wells 24 hpi (Figure 3A). Input condition (light green bar) represents the infection rate before adhesion and was set to $100 \%$. ICAM-1 as well as fibronectin increased the ratio of HCMV-positive cells among the adherent fractions (second and third green bar), demonstrating that HCMV-positive mDCs adhere stronger to both ligands.

To investigate whether this increased adhesion might be due to an enhanced expression of the $\beta 2$-integrin subunits, CD11a, CD11b, CD11c or CD18, flow cytometric analyses of mock-, HCMV-, or HCMV-UV-infected mDCs were performed $24 \mathrm{hpi}$ (Figure 3B). Expression of the indicated subunits was comparable between mock (white bars), HCMV-positive (green bars), HCMV-negative (black bars), and HCMV-UV-infected (gray bars) mDCs.

Since we previously demonstrated that increased ICAM-1 and fibronectin adhesion of HSV-1-infected mDCs is based on the induced $\beta 2$-integrin activity (45), we next examined the activation status of $\beta 2$-integrins after HCMV infection using an antibody which recognizes a conformational epitope only present on activated $\beta 2$-integrins (56-58). As a positive control we treated the cells with $\mathrm{Mg} / \mathrm{EGTA}$ to induce $\beta 2$-integrin activity via alteration of divalent cation concentration, since it is known that $\mathrm{Mg}^{2+}$ promotes transition from the inactive into the active conformational state $(52,59,60)$. Flow cytometric analyses of untreated mock (white bar) and HCMV-positive (green bar) $\mathrm{mDCs}$ revealed a significant induction of $\beta 2$-integrin activity of approximately 2.5-fold, while HCMV-negative (black bar) mDCs show a less pronounced induction (Figure $3 \mathrm{C}$ ). No differences in $\beta 2$-integrin activity were observed comparing mock and HCMVUV-infected mDCs (gray bar). As expected, treatment with $\mathrm{Mg} / \mathrm{EGTA}$ showed a strong increase in $\beta 2$-integrin activity in mock, HCMV-negative, and HCMV-UV condition. Interestingly, $\mathrm{Mg} / \mathrm{EGTA}$ treatment of HCMV-infected cells further increased the activation status of $\beta 2$-integrins on HCMV-positive mDCs compared to their untreated counterparts.

In order to analyze whether the observed increase in $\beta 2$-integrin activity shown in Figure $3 \mathrm{C}$ correlates with induced adhesion, a fibronectin adhesion assay was conducted (Figure 3D). In agreement with the activation status of $\beta 2$-integrins on HCMVpositive mDCs, we observed a significant induction in fibronectin adhesion compared to mock cells, while this was not detected for HCMV-negative and HCMV-UV-infected mDCs. Moreover, $\mathrm{Mg} /$ EGTA-treated cells adhered stronger to fibronectin compared to their respective untreated counterparts.

In order to evaluate whether the induced adhesion of HCMVpositive mDCs accounts for the reduced CCL19 transwell migration (Figure 1B), we performed a transwell migration assay with $\mathrm{Mg} / \mathrm{EGTA}$-treated mock cells to induce adhesion in the absence of viral infection (Figure 3E). Treatment with Mg/EGTA strongly reduced spontaneous and CCL19-directed chemotaxis comparable to the reduction observed for HCMV-positive mDCs (Figure 1B), while additional HCMV infection did not further reduce CCL19 transwell migration.

Therefore, we conclude that HCMV activates $\beta 2$-integrins on infected $\mathrm{mDC}$ to facilitate increased adhesion to fibronectin as well as ICAM-1, which in turn leads to reduced CCL19-mediated transwell migration.

\section{HCMV Infection of mDCs Leads to Decreased Expression Levels of CYTIP, the Negative Regulator of $\beta 2$-Integrin Activation}

Next, we aimed to unravel the molecular mechanism of the observed $\beta 2$-integrin activation on HCMV-positive mDCs. Cytohesin-1 is known to bind to the intracellular CD18 tail of $\beta 2$-integrins and thereby causes a conformational change leading to their activation $(28,29,34)$. Furthermore, it was demonstrated that the cellular protein CYTIP negatively regulates LFA-1 activity and consequently ICAM-1 adhesion $(30,45)$. In particular, using siRNA-mediated CYTIP ablation, it was previously shown that the loss of CYTIP suffices to induce mDC adhesion and reduce migration capability (45). Therefore, we next investigated cytohesin-1 and CYTIP expression in HCMV-infected mDCs. In this regard, mDCs were mock- or HCMV-infected and subjected to FACS, based on their GFP/YFP expression. As a control, HSV-1-infected mDCs were analyzed; however, due to the high infection efficiency of nearly $100 \%$, cell sorting was dispensable in this case. Confirming previous results, CYTIP protein levels were lost in HSV-1-infected mDCs 24 hpi (Figure 4A shows one representative experiment and Figure $4 \mathrm{C}$ summarizes the quantification of at least three independent experiments). In contrast, protein expression of cytohesin-1, which is the positive regulator of LFA-1 activity, is only affected to a minor extent. Interestingly, also in HCMV-positive mDCs CYTIP protein expression levels are reduced to approximately 50\% (24 hpi), while cytohesin-1 protein expression is not significantly influenced (Figures 4B,C).

Thus, these results provide evidence that HCMV induces downregulation of CYTIP in order to increase LFA-1 activation on the surface of infected mDCs leading to induced adhesion and reduced migration.

\section{HCMV Induces CYTIP Downmodulation Early after Infection}

Since it is known that HCMV replicates slower than HSV-1, we analyzed CYTIP downregulation at different time points post-infection. Therefore, mDCs were mock- or HCMV-infected for the indicated time periods and subsequently subjected to 


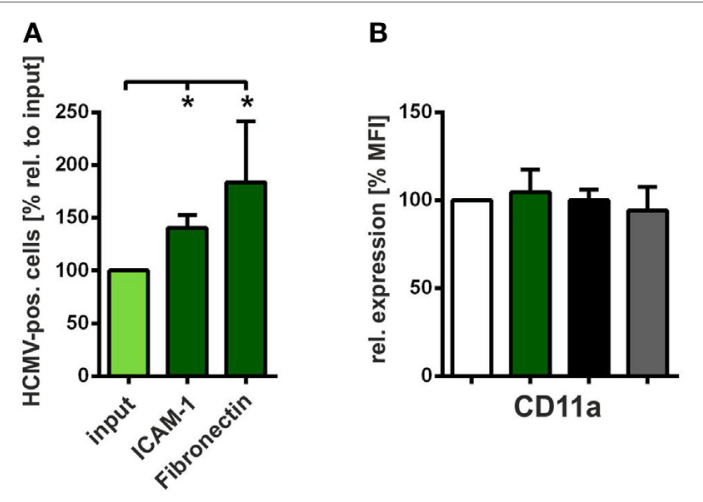

C

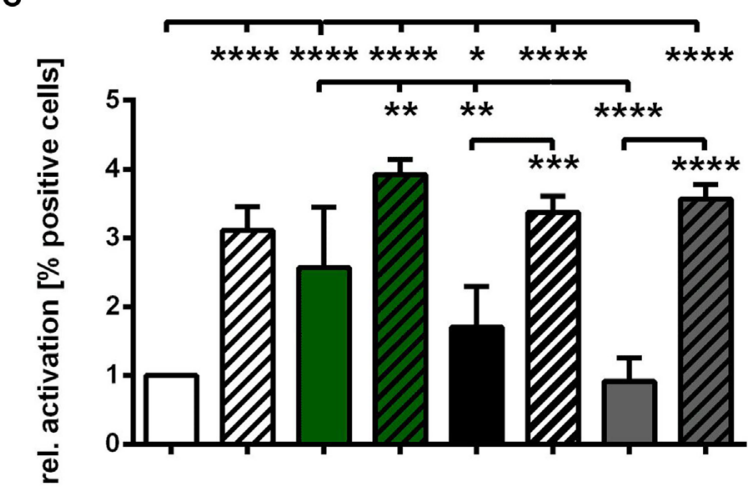

$\mathbf{E}$

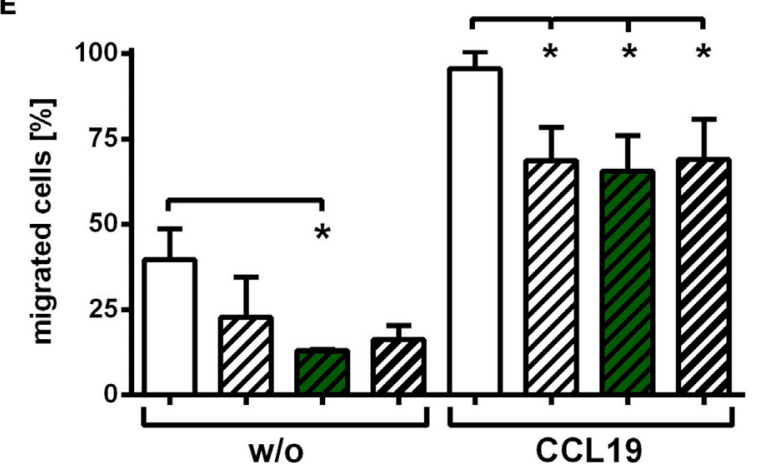

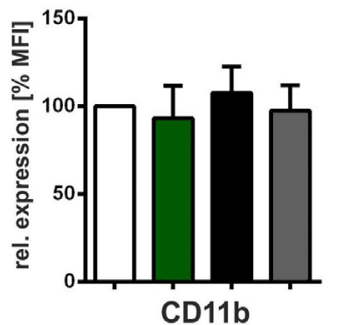
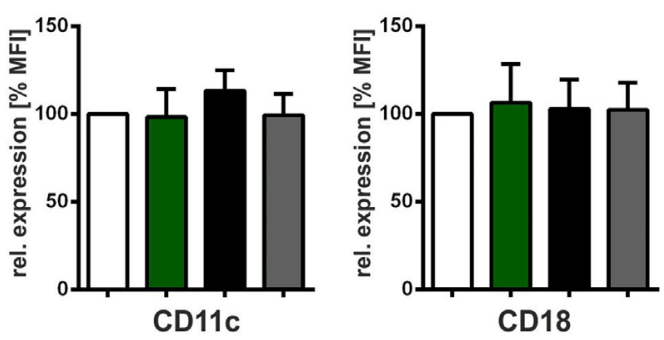

D

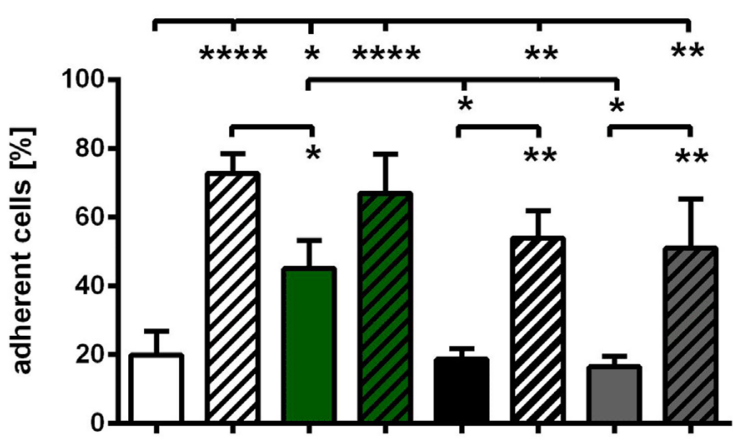

FIGURE 3 | Human cytomegalovirus (HCMV) increases activation of $\beta 2$-integrins thereby inducing mature DCs (mDCs) adhesion and reducing $\mathrm{mDC}$ transwell migration. (A) Mature dendritic cells (DCs) were HCMV-infected and subjected to ICAM-1 or fibronectin adhesion assays 24 hpi. Infection rates were determined before adhesion (input condition, light green bar) and after ICAM-1 $(n=5)$ or fibronectin $(n=3)$ adhesion (green bars). Infection rate before adhesion (input) was set to $100 \%$ and relative changes of infection rates in the adherent fractions are shown. (B) Mock-, HCMV-, or HCMV-ultraviolet (UV)-infected mDCs were harvested $24 \mathrm{hpi}$, stained with antibodies specific for CD11a/b/c or CD18 and analyzed via flow cytometry. Uninfected mock cells (white bar) were set to $100 \%$ and relative expression as mean fluorescence intensity for HCMV-positive (green bars), HCMV-negative (black bars), and HCMV-UV-infected (gray bars) mDCs are shown ( $n=3$ ). (C) Mock-, HCMV-, or HCMV-UV-infected mDCs were harvested 24 hpi and treated with (striped bars) or without Mg/EGTA (filled bars). Subsequently, cells were stained with an antibody specific for an epitope specifically present on activated CD11/CD18 ( $\beta 2$ ) integrins and subjected to flow cytometric analyses. Mock (white bar) was set to "1," and relative activation is shown for the indicated conditions. The experiment was performed at least three times with cells of different healthy donors. (D) Mature DCs were infected and treated with (striped bars) or without Mg/EGTA (filled bars) as described in (C) and subjected to fibronectin adhesion assay. Percentages of adherent cells are depicted for each condition $(n=3)$. (E) Mock- or HCMV-infected mDCs (24 hpi) were treated with Mg/EGTA (striped bars) and subjected to transwell migration assays. For induction of chemotaxis, CCL19 (100 ng/ml) was added to the lower wells, while spontaneous migration without chemokine was analyzed as control (w/o). Migration was evaluated after $2 \mathrm{~h}$. The percentages of migrated mDCs were calculated in the lower well by determining cell number and infection rates of migrated cells in relation to the respective starting condition. Untreated mock cells are depicted as control (white bars). The experiment was performed with cells of three different healthy donors. Only significant changes ( ${ }^{\star \star \star \star}=p<0.0001$; $\left.{ }^{\star \star \star}=p<0.001 ;{ }^{\star \star}=p<0.01 ;{ }^{*}=p<0.05\right)$ are marked by asterisks. 

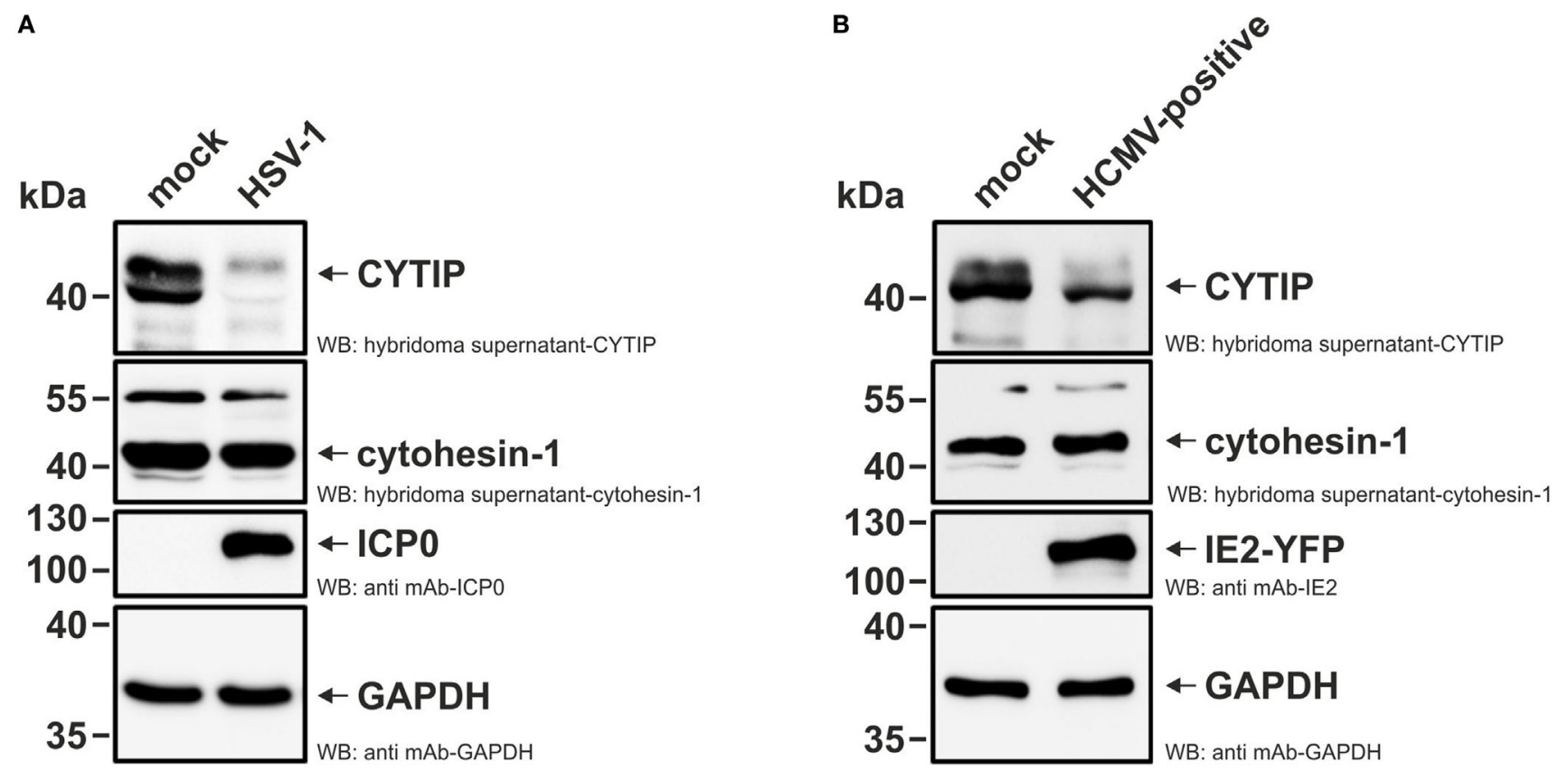

C

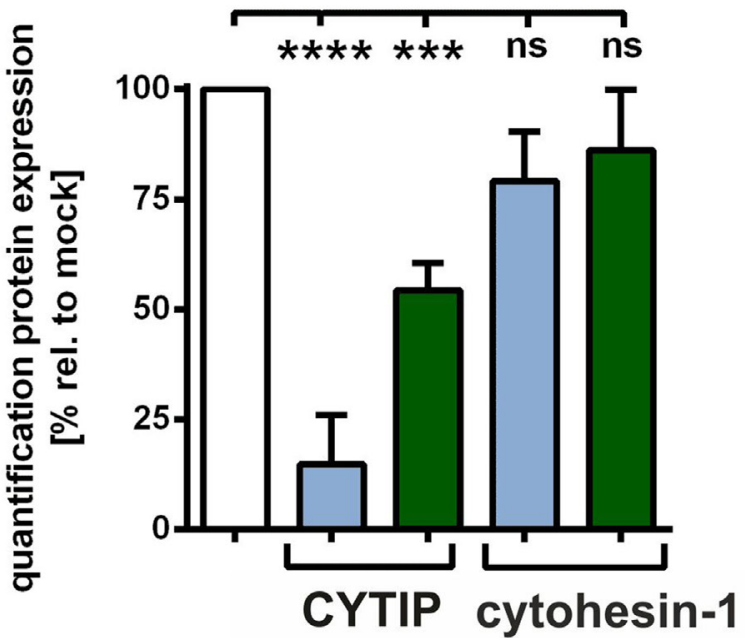

mock

HSV-1

HCMV-positive

FIGURE 4 | Human cytomegalovirus (HCMV) infection of mature dendritic cells (mDCs) leads to decreased CYTIP expression levels. (A) mDCs were either mock- or herpes simplex virus type 1 (HSV-1)-infected and harvested 24 hpi, (B) mock- or HCMV-infected and sorted based on their green fluorescence protein expression $24 \mathrm{hpi}$. (A,B) Protein lysates were prepared and subjected to Western blot analyses with antibodies specific for CYTIP, cytohesin-1, ICPO, IE2, or GAPDH. One representative experiment out of at least three is shown. (C) Quantification of CYTIP and cytohesin-1 protein expression levels in HSV-1-infected or HCMV-positive mDCs, summarizing at least three independent experiments. Expression of CYTIP and cytohesin-1 was normalized to the GAPDH control. Mock was set to $100 \%$. Significant changes $\left.{ }^{* \star \star \star}=p<0.0001{ }^{* \star *}=p<0.001\right)$ are marked by asterisks, non-significant changes $(p>0.05)$ as "ns."

intracellular flow cytometric analyses for detection of CYTIP and cytohesin-1 levels (Figure 5). One representative experiment for HCMV-positive (green histograms) and HCMV-negative (filled black histograms) $\mathrm{mDCs}$ is shown in Figures $\mathbf{5 A}, \mathbf{C}$, respectively. Summarized data out of at least three independent experiments are depicted as median values relative to mock in Figure 5B (HCMV-positive) and Figure 5D (HCMV-negative). CYTIP reduction is already observed $12 \mathrm{hpi}$ in HCMV-positive mDCs, becoming statistically significant $24 \mathrm{hpi}$ and even more prominent 36 hpi with a reduction of approximately $70 \%$ in comparison to mock-infected cells (Figure 5B). In contrast, cytohesin-1 is not downregulated to a significant extent, even $36 \mathrm{~h}$ post-HCMV infection. HCMV-negative mDCs showed no reduction in CYTIP and cytohesin-1 protein levels until $36 \mathrm{hpi}$ (Figure 5D).

We, therefore, conclude that HCMV specifically downregulates CYTIP protein expression, while cytohesin-1 levels are not impaired. 


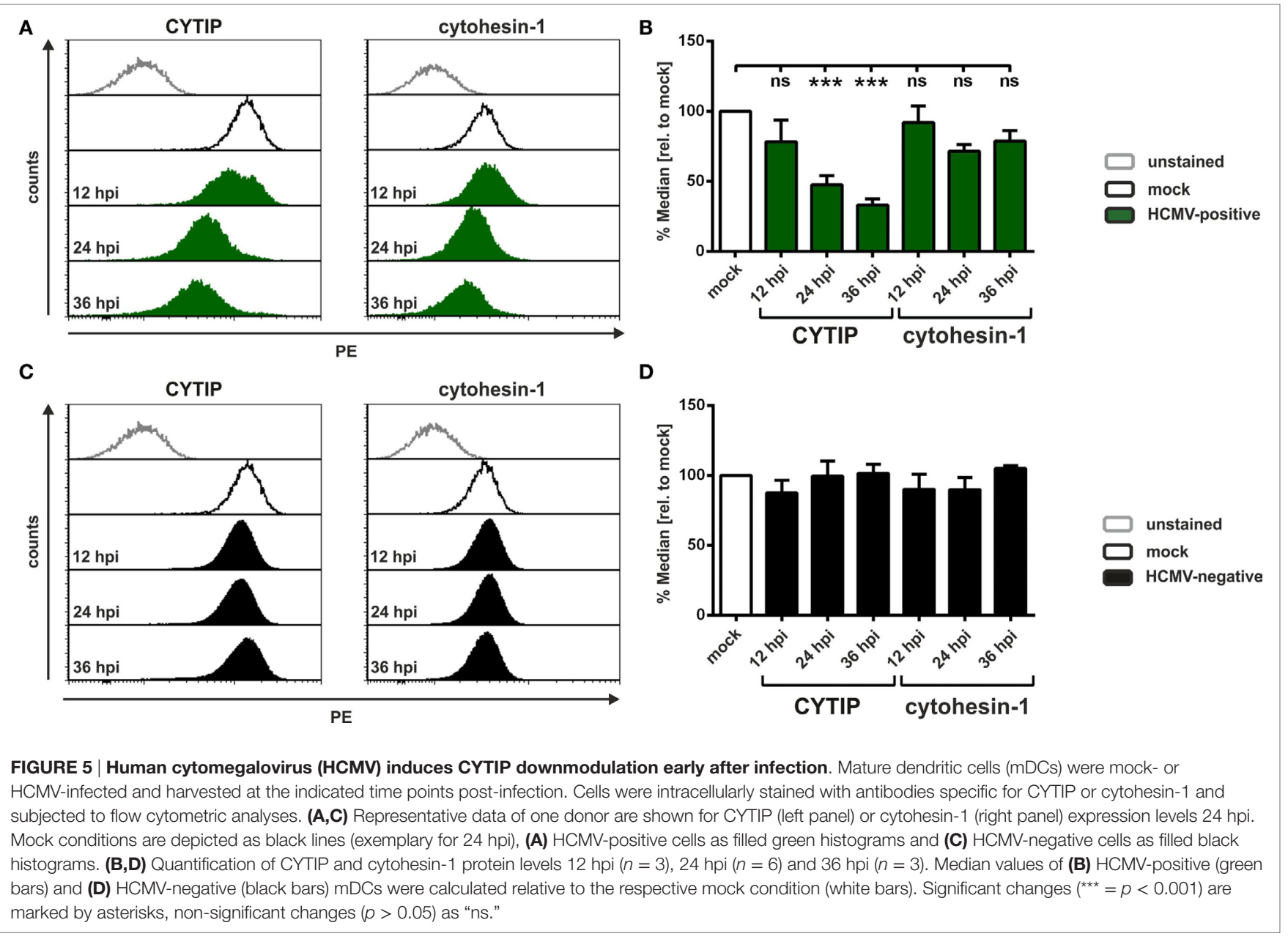

\section{HCMV Induces a Proteasome- Dependent Degradation of CYTIP in mDCs}

We further investigated the mechanism by which HCMV mediates CYTIP downmodulation. Since our previous findings in HSV-1-infected mDCs showed a proteasome-dependent pathway of CYTIP degradation (45), we examined whether a similar mechanism is responsible for CYTIP downmodulation in the context of an HCMV infection. Thus, mDCs were mock- or HCMV-infected for $24 \mathrm{~h}$, treated with or without the proteasome inhibitor MG-132 and analyzed for their CYTIP as well as cytohesin-1 expression via intracellular flow cytometry (Figures 6A,B). One representative experiment is depicted in Figure 6A, which shows CYTIP (left panel) and cytohesin-1 (right panel) protein levels in HCMV-positive (green histograms) and HCMV-negative (black histograms) mDCs 24 hpi. Figure 6B summarizes the flow cytometric data from at least three independent experiments.

Remarkably, CYTIP protein expression levels were restored in MG-132-treated HCMV-positive mDCs (green striped pattern) to approximately $80 \%$. Regarding cytohesin- 1 , no significant differences in protein expression levels could be observed. CYTIP and cytohesin-1 protein levels are not affected in HCMV-negative mDCs compared to mock (Figure 6B, right panel). These observations are confirmed by immunofluorescence microscopy analyzing CYTIP and cytohesin-1 expression in mock- and HCMV-infected mDCs 24 hpi with or without MG-132 treatment (Figure 6C).

Taken together, our present study demonstrates that HCMV induces a proteasomal degradation of CYTIP in HCMV-positive mDCs early after infection. This leads to induced $\beta 2$-integrin activation, and therefore increased $\mathrm{mDC}$ adhesion, which in turn inhibits CCL19-directed mDC transwell migration. Thus, not only the $\alpha$-herpesvirus HSV- 1 but also the $\beta$-herpesvirus HCMV uses this strategy to hamper the induction of antiviral immune responses. However, since HCMV does not downregulate the expression of CCR7, the reduction of CCL19-mediated migration is most likely due to induced adhesion.

\section{DISCUSSION}

Dendritic cells play a crucial role in the orchestration of immune responses by transferring the immunological status of peripheral tissues to areas with high lymphocyte density, i.e., to SLOs. There 


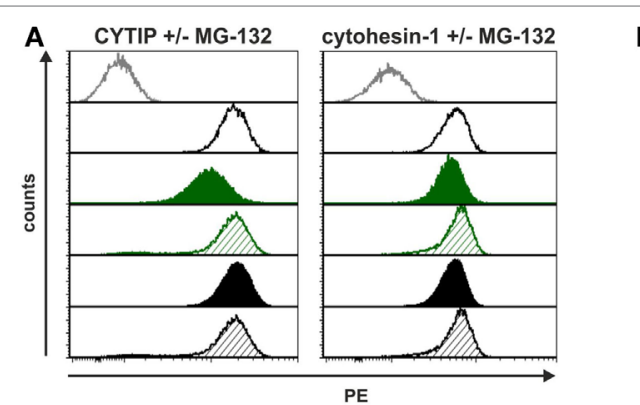

C

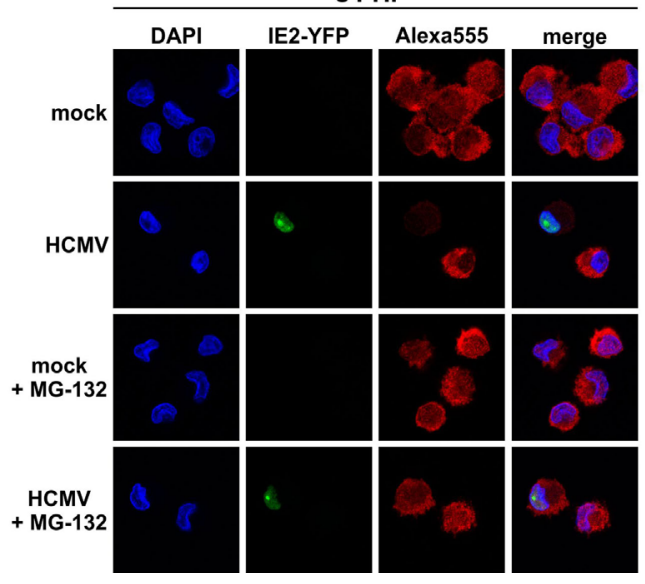

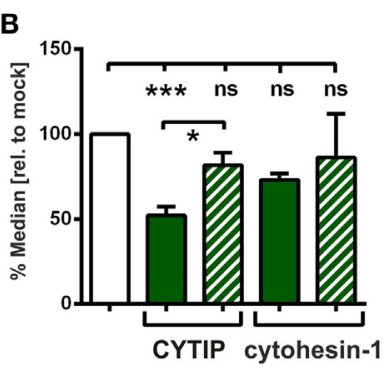
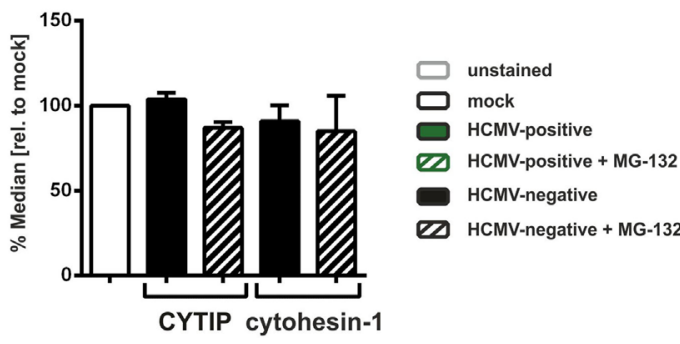

cytohesin-1

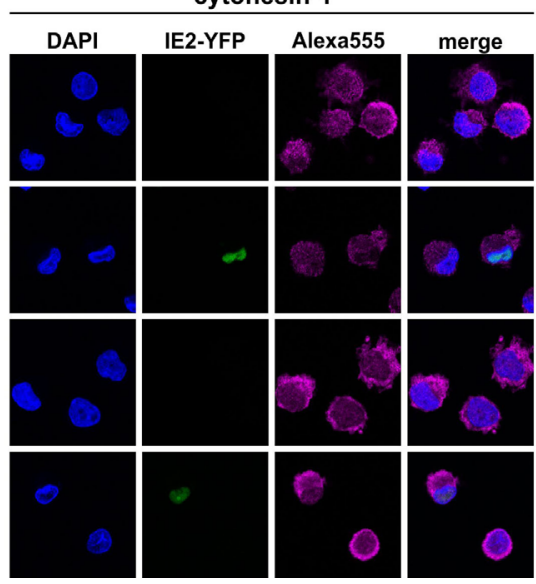

FIGURE 6 | In human cytomegalovirus (HCMV)-infected mature DCs (mDCs) CYTIP is degraded via the proteasome. Mature dendritic cells were mock- or HCMV-infected, treated with or without MG-132 and harvested 24 hpi. (A,B) Subsequently, intracellular staining with antibodies specific for CYTIP or cytohesin-1 was performed, and samples were subjected to flow cytometric analyses. (A) One representative experiment is shown for CYTIP (left panel) or cytohesin-1 (right panel) levels. Mock conditions (black lined histograms), HCMV-positive cells (green filled histograms), and HCMV-negative cells (black filled histograms) are shown, while the respective MG-132-treated samples are depicted as striped histograms. (B) Summarized data of at least three independent experiments of CYTIP and cytohesin-1 protein levels, analyzed via intracellular flow cytometry. Median values of HCMV-positive mDCs with and without MG-132 treatment (green filled and green striped bars, respectively; left panel) as well as HCMV-negative mDCs with and without MG-132 treatment (black filled and black striped, respectively; right panel) were calculated relative to the respective mock conditions with and without MG-132 (white bars, set to $100 \%$ ). Significant changes $\left(^{\star \star \star}=p<0.001 ;^{*}=p<0.05\right)$ are marked by asterisks, non-significant changes ( $\left.p>0.05\right)$ as "ns." (C) Immunofluorescence staining of CYTIP (left panel) and cytohesin-1 (right panel). The IE2-YFP fusion protein of the HCMV TB40E/IE2-EYFP strain allows direct determination of HCMV-positive and HCMV-negative cells. The nucleus was visualized using DAPI. The experiment was performed three times and representative data are shown.

(naïve) $\mathrm{T}$ cells and/or B cells can be activated by presentation of antigens on DCs, in order to induce a potent immune response. Considering this, migration of DCs is a prerequisite for the successful initiation of adaptive immunity, important for elimination of e.g., viral infections. Particularly herpesviruses, which are able to establish lifelong persistent infections, have developed several strategies to counteract elimination by the immune system. In this study, we provide evidence that HCMV induces the activation of $\beta 2$-integrins via the proteasomal degradation of the negative regulator CYTIP. This degradation of CYTIP is functionally relevant as we found induced adhesion and impaired transwell migration of HCMV-infected mDCs toward the chemokine CCL19, which is known to be predominantly expressed in lymph nodes. Therefore, immune evasion mechanisms targeting DC migration may allow HCMV to effectively evade cell-mediated immunity in vivo, supporting the production of new progeny virus and the establishment of latency.

Our finding that HCMV inhibits CCL19-mediated migration (Figure 1B) is the first report in which HCMV was described to reduce $\mathrm{mDC}$ migration toward this specific chemokine exclusively via the induction of adhesion, i.e., by increasing the activation status of $\beta 2$-integrins (Figure 3). Thus, HCMV is able to not only inhibit upregulation of the respective chemokine receptor CCR7, when infecting iDCs prior to maturation (61), but also hamper migration toward CCL19 beyond CCR7-targeting, via the induction of adhesion upon HCMV infection of mDCs (Figures 3D,E). This very likely caused the reduced CCL19-mediated migration using fibronectin-coated membranes, as expression of the CCL19-receptor CCR7 was not affected by HCMV until 24 hpi (Figure 2B). Adhesion is mediated by integrins, thus we investigated the activation status of $\beta 2$-integrins in uninfected or HCMV-infected mDCs, since our group previously showed that fibronectin adhesion of $\mathrm{mDCs}$ is predominantly mediated by the $\beta 2$-integrin LFA- 1 (45). Interestingly, HCMV-positive mDCs exhibit significantly increased activation of $\beta 2$-integrins, similar to that of $\mathrm{Mg} / \mathrm{EGTA}$-treated $\mathrm{mDCs}$, in comparison to mock cells (Figure 3C), which in turn resulted in a strong induction of fibronectin adhesion (Figure 3D). Additionally, adhesion of 
HCMV-infected mDCs on the LFA-1 specific ligand ICAM-1 was also strongly induced 24 hpi (Figure 3A). This hints toward a mechanism by which HCMV upregulates $\beta 2$-integrin activation, i.e., LFA-1, and thus $\mathrm{mDC}$ adhesion in order to reduce migration. HSV-1-infected mDCs also showed impaired CCL19-mediated chemotaxis, however, to a far greater extent than for HCMV. This HSV-1-mediated inhibition of CCL19-specific-migration was not only due to stronger mDC adhesion upon HSV-1 infection, but also based on a decrease in CCR7 surface expression $(44,45)$.

In contrast to the reduced CCL19-mediated migration in HCMV-positive mDCs, we could not observe changes in CXCL12-mediated chemotaxis compared to mock, HCMVnegative or HCMV-UV-infected mDCs (Figure 1B). Strikingly, the surface expression of the respective chemokine receptor CXCR4 was found to be significantly induced on HCMV-positive $\mathrm{mDCs}$ (Figure 2D). Previous reports demonstrated that infection of different cell types with HCMV has diverse effects on CXCR4. Lecointe et al. showed that HCMV infection of microglial cells, but not of macrophages or astrocytes, leads to the downregulation of CXCR4 (62). Moreover, CXCL12-mediated migration of HCMV-infected cytotrophoblasts was found to be impaired, although CXCR4 surface expression was induced (63). Hence, it is tempting to speculate that HCMV may differentially regulate the CXCR4 axis in a cell-type specific manner. In addition, high expression of CXCL12, recognized by CXCR4, by osteoblasts in the bone marrow could explain why HCMV does not influence the migration toward this chemokine. In particular, HCMV is known to establish latency in $\mathrm{CD}_{3} 4^{+}$hematopoietic progenitor cells (39-41) and CD14+ monocytes $(42,43)$, and therefore, this directed migration of HCMV-infected mDCs to the bone marrow could stimulate dissemination and translocation to an ecological niche rich in potential target cells and thereby increase the reservoir of latently infected myeloid progenitor cells. Considering that HCMV uses multiple strategies to modulate DC migration by, e.g., regulating host chemokine receptor expression as well as expressing a plethora of chemokine and chemokine receptor homologs itself, it emphasizes the crucial role to attack the migratory ability of DCs to hamper early immune responses of the host.

The inside-out-signaling for $\beta 2$-integrin activation is known to be based on intracellular binding of talin or cytohesin- 1 to the CD18 subdomain and to membrane-bound PIP3 $(27,33,64)$. Cytohesin- 1 is a specific binding partner for the family of $\beta 2$ integrins and highly expressed in mDCs (64). Consistent with our previous report on HSV-1-infected mDCs (45), cytohesin-1 protein expression was not significantly affected by HCMV infection (Figures 4 and 5). In contrast of directly regulating cytohesin-1 expression, the Kaposi's sarcoma-associated herpesvirus cytohesin-1 homolog kaposin A was found to modulate the subcellular localization of cytohesin-1. Kaposin A directly interacts with cytohesin- 1 to induce its membrane localization, finally leading to increased ICAM-1 adhesion (65). However, HCMV does not encode a kaposin A homolog, and thus, alternative mechanisms must be induced. Apart from a regulation of cytohesin-1 itself, we tested whether HCMV influences the expression of CYTIP, which is the direct interaction partner of cytohesin-1 and mediates the abrogation of cytohesin- 1 induced
LFA-1 activation (30). As recently shown by our group, the silencing of CYTIP indeed leads to induced $\mathrm{mDC}$ adhesion and reduced migration, hence CYTIP plays a crucial role in the regulation of adhesion and migration (45). Remarkably, we detected a strong proteasome-dependent degradation of CYTIP in HCMVpositive mDCs (Figure 6). Hence, we provide evidence that at least the prototypic members of $\alpha$ - and $\beta$-herpesviridae, HSV-1 and HCMV, respectively, share a similar mechanism to induce CYTIP degradation in order to induce adhesion and inhibit $\mathrm{mDC}$ migration.

The results presented here reveal that HCMV targets different aspects of DC biology, in particular adhesion and migration. By manipulating chemokine receptor expression and the activation status of integrins, HCMV impairs the migration of infected $\mathrm{mDCs}$ to block induction of antiviral immune responses. Further research concerning the molecular mechanism of CYTIP degradation in HCMV-infected mDCs and, thus, a better understanding of this viral immune evasive mechanism might lead to the development of new anti-herpesviral therapeutics.

\section{ETHICS STATEMENT}

For the generation of monocyte-derived DCs from leukapheresis products of healthy donors, a positive vote from the local ethics committee has been obtained (reference number 4556). This study was carried out in accordance with the recommendations of the ethics committee of the "Friedrich-Alexander-Universität Erlangen-Nürnberg" with written informed consent from all subjects. All subjects gave written informed consent in accordance with the Declaration of Helsinki.

\section{AUTHOR CONTRIBUTIONS}

LG, AS, and CH designed the study and the experiments. LG, CD, $\mathrm{PM}$, and LK performed experiments and analyzed and interpreted the data. VL and MT provided essential reagents. LG wrote the paper. $\mathrm{CH}, \mathrm{AS}, \mathrm{PM}, \mathrm{VL}$, and MT critically revised the manuscript. All authors approved the final version of the manuscript.

\section{ACKNOWLEDGMENTS}

We thank Elisabeth Kremmer (Helmholtz Center Munich, Munich, Germany) for providing us with anti-cytohesin-1 and anti-CYTIP antibodies and Prof. Thomas Stamminger (Institute for Clinical and Molecular Virology, Erlangen, Germany) for the HCMV TB40E/IE2-EYFP strain. We additionally thank the Core Unit "Cell Sorting and Immunomonitoring," from the University Hospital Erlangen, for cell sorting.

\section{FUNDING}

This work was supported by the Deutsche Forschungsgemeinschaft (DFG) via the SFB796 (project B2). LG and CH were supported by the ELAN fonds (15-12-22-1-Heilingloh). VL and MT receive funding from the DFG via TRR60 project A7N, GRK1949 project 13, and from the Medical Faculty of the University DuisburgEssen via the IFORES-Sonderprogramm. 


\section{REFERENCES}

1. Banchereau J, Steinman RM. Dendritic cells and the control of immunity. Nature (1998) 392:245-52. doi:10.1038/32588

2. Lanzavecchia A, Sallusto F. The instructive role of dendritic cells on T cell responses: lineages, plasticity and kinetics. Curr Opin Immunol (2001) 13:291-8. doi:10.1016/S0952-7915(00)00218-1

3. Steinman RM. The dendritic cell system and its role in immunogenicity. Annu Rev Immunol (1991) 9:271-96. doi:10.1146/annurev.iy.09.040191.001415

4. Banchereau J, Briere F, Caux C, Davoust J, Lebecque S, Liu YJ, et al. Immunobiology of dendritic cells. Annu Rev Immunol (2000) 18:767-811. doi:10.1146/annurev.immunol.18.1.767

5. Wilson NS, Villadangos JA. Lymphoid organ dendritic cells: beyond the Langerhans cells paradigm. Immunol Cell Biol (2004) 82:91-8. doi:10.1111/ j.1440-1711.2004.01216.x

6. Watts C, Zaru R, Prescott AR, Wallin RP, West MA. Proximal effects of tolllike receptor activation in dendritic cells. Curr Opin Immunol (2007) 19:73-8. doi:10.1016/j.coi.2006.11.014

7. Delgado E, Finkel V, Baggiolini M, Mackay CR, Steinman RM, GranelliPiperno A. Mature dendritic cells respond to SDF-1, but not to several beta-chemokines. Immunobiology (1998) 198:490-500. doi:10.1016/S01712985(98)80073-9

8. Randolph GJ, Ochando J, Partida-Sanchez S. Migration of dendritic cell subsets and their precursors. Annu Rev Immunol (2008) 26:293-316. doi:10.1146/ annurev.immunol.26.021607.090254

9. Sallusto F, Schaerli P, Loetscher P, Schaniel C, Lenig D, Mackay CR, et al. Rapid and coordinated switch in chemokine receptor expression during dendritic cell maturation. Eur J Immunol (1998) 28:2760-9. doi:10.1002/ (SICI)1521-4141(199809)28:09<2760::AID-IMMU2760>3.0.CO;2-N

10. Sozzani S, Allavena P, D’Amico G, Luini W, Bianchi G, Kataura M, et al. Differential regulation of chemokine receptors during dendritic cell maturation: a model for their trafficking properties. J Immunol (1998) 161:1083-6.

11. Nagasawa T. CXCL12/SDF-1 and CXCR4. Front Immunol (2015) 6:301. doi:10.3389/fimmu.2015.00301

12. Ponten F, Jirstrom K, Uhlen M. The human protein atlas - a tool for pathology. J Pathol (2008) 216:387-93. doi:10.1002/path.2440

13. Förster R, Schubel A, Breitfeld D, Kremmer E, Renner-Muller I, Wolf E, et al. CCR7 coordinates the primary immune response by establishing functional microenvironments in secondary lymphoid organs. Cell (1999) 99:23-33. doi:10.1016/S0092-8674(00)80059-8

14. Parlato S, Santini SM, Lapenta C, Di PT, Logozzi M, Spada M, et al. Expression of CCR-7, MIP-3beta, and Th-1 chemokines in type I IFNinduced monocyte-derived dendritic cells: importance for the rapid acquisition of potent migratory and functional activities. Blood (2001) 98:3022-9. doi:10.1182/blood.V98.10.3022

15. Ridley AJ. Rho GTPases and cell migration. J Cell Sci (2001) 114:2713-22.

16. Myers KR, Casanova JE. Regulation of actin cytoskeleton dynamics by Arf-family GTPases. Trends Cell Biol (2008) 18:184-92. doi:10.1016/j.tcb. 2008.02.002

17. Truong H, Danen EH. Integrin switching modulates adhesion dynamics and cell migration. Cell Adh Migr (2009) 3:179-81. doi:10.4161/cam.3.2.8036

18. Van Haastert PJ, Devreotes PN. Chemotaxis: signalling the way forward. Nat Rev Mol Cell Biol (2004) 5:626-34. doi:10.1038/nrm1435

19. Hynes RO. Integrins: bidirectional, allosteric signaling machines. Cell (2002) 110:673-87. doi:10.1016/S0092-8674(02)00971-6

20. Hogg N, Henderson R, Leitinger B, McDowall A, Porter J, Stanley P. Mechanisms contributing to the activity of integrins on leukocytes. Immunol Rev (2002) 186:164-71. doi:10.1034/j.1600-065X.2002.18614.x

21. Arnaout MA. Structure and function of the leukocyte adhesion molecules CD11/CD18. Blood (1990) 75:1037-50.

22. Smith CW. 3. Adhesion molecules and receptors. J Allergy Clin Immunol (2008) 121:S375-9. doi:10.1016/j.jaci.2007.07.030

23. Dustin ML, Springer TA. Role of lymphocyte adhesion receptors in transient interactions and cell locomotion. Annu Rev Immunol (1991) 9:27-66. doi:10.1146/annurev.iy.09.040191.000331

24. Grakoui A, Bromley SK, Sumen C, Davis MM, Shaw AS, Allen PM, et al. The immunological synapse: a molecular machine controlling $\mathrm{T}$ cell activation. Science (1999) 285:221-7. doi:10.1126/science.285.5425.221
25. Springer TA. Adhesion receptors of the immune system. Nature (1990) 346:425-34. doi:10.1038/346425a0

26. Diamond MS, Springer TA. The dynamic regulation of integrin adhesiveness. Curr Biol (1994) 4:506-17. doi:10.1016/S0960-9822(00)00111-1

27. Liddington RC, Ginsberg MH. Integrin activation takes shape. J Cell Biol (2002) 158:833-9. doi:10.1083/jcb.200206011

28. Geiger C, Nagel W, Boehm T, van KY, Figdor CG, Kremmer E, et al. Cytohesin-1 regulates beta-2 integrin-mediated adhesion through both ARF-GEF function and interaction with LFA-1. EMBO J (2000) 19:2525-36. doi:10.1093/emboj/19.11.2525

29. Kolanus W, Nagel W, Schiller B, Zeitlmann L, Godar S, Stockinger H, et al. Alpha L beta 2 integrin/LFA-1 binding to ICAM-1 induced by cytohesin-1, a cytoplasmic regulatory molecule. Cell (1996) 86:233-42. doi:10.1016/ S0092-8674(00)80095-1

30. Boehm T, Hofer S, Winklehner P, Kellersch B, Geiger C, Trockenbacher A, et al. Attenuation of cell adhesion in lymphocytes is regulated by CYTIP, a protein which mediates signal complex sequestration. EMBO J (2003) 22:1014-24. doi:10.1093/emboj/cdg101

31. MacNeil AJ, Pohajdak B. Getting a GRASP on CASP: properties and role of the cytohesin-associated scaffolding protein in immunity. Immunol Cell Biol (2009) 87:72-80. doi:10.1038/icb.2008.71

32. Tang P, Cheng TP, Agnello D, Wu CY, Hissong BD, Watford WT, et al. Cybr, a cytokine-inducible protein that binds cytohesin-1 and regulates its activity. Proc Natl Acad Sci U S A (2002) 99:2625-9. doi:10.1073/ pnas.052712999

33. Nagel W, Zeitlmann L, Schilcher P, Geiger C, Kolanus J, Kolanus W. Phosphoinositide 3-OH kinase activates the beta2 integrin adhesion pathway and induces membrane recruitment of cytohesin-1. J Biol Chem (1998) 273:14853-61. doi:10.1074/jbc.273.24.14853

34. Weber KS, Weber C, Ostermann G, Dierks H, Nagel W, Kolanus W. Cytohesin-1 is a dynamic regulator of distinct LFA-1 functions in leukocyte arrest and transmigration triggered by chemokines. Curr Biol (2001) 11:1969-74. doi:10.1016/S0960-9822(01)00597-8

35. Cannon MJ, Schmid DS, Hyde TB. Review of cytomegalovirus seroprevalence and demographic characteristics associated with infection. Rev Med Virol (2010) 20:202-13. doi:10.1002/rmv.655

36. Crough $\mathrm{T}$, Khanna R. Immunobiology of human cytomegalovirus: from bench to bedside. Clin Microbiol Rev (2009) 22:76-98, Table of Contents. doi:10.1128/CMR.00034-08

37. Revello MG, Gerna G. Human cytomegalovirus tropism for endothelial/ epithelial cells: scientific background and clinical implications. Rev Med Virol (2010) 20:136-55. doi:10.1002/rmv.645

38. Sinzger C. Entry route of HCMV into endothelial cells. J Clin Virol (2008) 41:174-9. doi:10.1016/j.jcv.2007.12.002

39. Hahn G, Jores R, Mocarski ES. Cytomegalovirus remains latent in a common precursor of dendritic and myeloid cells. Proc Natl Acad Sci U S A (1998) 95:3937-42. doi:10.1073/pnas.95.7.3937

40. Mendelson M, Monard S, Sissons P, Sinclair J. Detection of endogenous human cytomegalovirus in CD34+ bone marrow progenitors. J Gen Virol (1996) 77(Pt 12):3099-102. doi:10.1099/0022-1317-77-12-3099

41. Sindre H, Tjoonnfjord GE, Rollag H, Ranneberg-Nilsen T, Veiby OP, Beck S, et al. Human cytomegalovirus suppression of and latency in early hematopoietic progenitor cells. Blood (1996) 88:4526-33.

42. Hargett D, Shenk TE. Experimental human cytomegalovirus latency in CD14+ monocytes. Proc Natl Acad Sci U S A (2010) 107:20039-44. doi:10.1073/ pnas. 1014509107

43. Taylor-Wiedeman J, Sissons JG, Borysiewicz LK, Sinclair JH. Monocytes are a major site of persistence of human cytomegalovirus in peripheral blood mononuclear cells. J Gen Virol (1991) 72(Pt 9):2059-64. doi:10.1099/ 0022-1317-72-9-2059

44. Prechtel AT, Turza NM, Kobelt DJ, Eisemann JI, Coffin RS, McGrath Y, et al. Infection of mature dendritic cells with herpes simplex virus type 1 dramatically reduces lymphoid chemokine-mediated migration. J Gen Virol (2005) 86:1645-57. doi:10.1099/vir.0.80852-0

45. Theodoridis AA, Eich C, Figdor CG, Steinkasserer A. Infection of dendritic cells with herpes simplex virus type 1 induces rapid degradation of CYTIP, thereby modulating adhesion and migration. Blood (2011) 118:107-15. doi:10.1182/blood-2010-07-294363 
46. Pfeiffer IA, Zinser E, Strasser E, Stein MF, Dorrie J, Schaft N, et al. Leukoreduction system chambers are an efficient, valid, and economic source of functional monocyte-derived dendritic cells and lymphocytes. Immunobiology (2013) 218:1392-401. doi:10.1016/j.imbio.2013.07.005

47. Kummer M, Turza NM, Muhl-Zurbes P, Lechmann M, Boutell C, Coffin RS, et al. Herpes simplex virus type 1 induces CD83 degradation in mature dendritic cells with immediate-early kinetics via the cellular proteasome. J Virol (2007) 81:6326-38. doi:10.1128/JVI.02327-06

48. Heilingloh CS, Muhl-Zurbes P, Steinkasserer A, Kummer M. Herpes simplex virus type 1 ICP0 induces CD83 degradation in mature dendritic cells independent of its E3 ubiquitin ligase function. J Gen Virol (2014) 95:1366-75. doi:10.1099/vir.0.062810-0

49. Sodeik B, Ebersold MW, Helenius A. Microtubule-mediated transport of incoming herpes simplex virus 1 capsids to the nucleus. J Cell Biol (1997) 136:1007-21. doi:10.1083/jcb.136.5.1007

50. Wagenknecht N, Reuter N, Scherer M, Reichel A, Muller R, Stamminger T. Contribution of the major ND10 proteins PML, hDaxx and Sp100 to the regulation of human cytomegalovirus latency and Lytic replication in the monocytic cell line THP-1. Viruses (2015) 7:2884-907. doi:10.3390/ v7062751

51. Andreoni M, Faircloth M, Vugler L, Britt WJ. A rapid microneutralization assay for the measurement of neutralizing antibody reactive with human cytomegalovirus. J Virol Methods (1989) 23:157-67. doi:10.1016/0166-0934(89) 90129-8

52. Guan S, Cheng M, Law SK. The integrin alphaL leg region controls the Mg/ EGTA mediated activation of LFA-1. Biochem Biophys Res Commun (2015) 458:251-5. doi:10.1016/j.bbrc.2015.01.094

53. Anceriz N, Vandal K, Tessier PA. S100A9 mediates neutrophil adhesion to fibronectin through activation of beta2 integrins. Biochem Biophys Res Commun (2007) 354:84-9. doi:10.1016/j.bbrc.2006.12.203

54. Johansson S, Svineng G, Wennerberg K, ArmulikA, Lohikangas L. Fibronectinintegrin interactions. Front Biosci (1997) 2:d126-46. doi:10.2741/A178

55. Diamond MS, Staunton DE, de Fougerolles AR, Stacker SA, Garcia-Aguilar J, Hibbs ML, et al. ICAM-1 (CD54): a counter-receptor for Mac-1 (CD11b/ CD18). J Cell Biol (1990) 111:3129-39. doi:10.1083/jcb.111.6.3129

56. Dougherty GJ, Dransfield I, Hogg N. Identification of a novel monocyte cell surface molecule involved in the generation of antigen-induced proliferative responses. Eur J Immunol (1988) 18:2067-71. doi:10.1002/eji.1830181229

57. Hogg N, Selvendran Y. An anti-human monocyte/macrophage monoclonal antibody, reacting most strongly with macrophages in lymphoid tissue. Cell Immunol (1985) 92:247-53. doi:10.1016/0008-8749(85)90006-1
58. Salas A, Shimaoka M, Kogan AN, Harwood C, Von Andrian UH, Springer TA Rolling adhesion through an extended conformation of integrin alphaLbeta2 and relation to alpha I and beta I-like domain interaction. Immunity (2004) 20:393-406. doi:10.1016/S1074-7613(04)00082-2

59. Hogg N, Bennett R, Cabanas C, Dransfield I. Leukocyte integrin activation. Kidney Int (1992) 41:613-6. doi:10.1038/ki.1992.93

60. Stewart M, Hogg N. Regulation of leukocyte integrin function: affinity vs. avidity.J Cell Biochem (1996)61:554-61.doi:10.1002/(SICI)1097-4644(19960616) 61:4<554::AID-JCB8>3.0.CO;2-N

61. Moutaftsi M, Brennan P, Spector SA, Tabi Z. Impaired lymphoid chemokinemediated migration due to a block on the chemokine receptor switch in human cytomegalovirus-infected dendritic cells. J Virol (2004) 78:3046-54. doi:10.1128/JVI.78.6.3046-3054.2004

62. Lecointe D, Dugas N, Leclerc P, Hery C, Delfraissy JF, Tardieu M. Human cytomegalovirus infection reduces surface CCR5 expression in human microglial cells, astrocytes and monocyte-derived macrophages. Microbes Infect (2002) 4:1401-8. doi:10.1016/S1286-4579(02)00022-9

63. Warner JA, Zwezdaryk KJ, Day B, Sullivan DE, Pridjian G, Morris CA. Human cytomegalovirus infection inhibits CXCL12-mediated migration and invasion of human extravillous cytotrophoblasts. Virol J (2012) 9:255. doi:10.1186/1743-422X-9-255

64. Quast T, Tappertzhofen B, Schild C, Grell J, Czeloth N, Forster R, et al. Cytohesin-1 controls the activation of RhoA and modulates integrindependent adhesion and migration of dendritic cells. Blood (2009) 113: 5801-10. doi:10.1182/blood-2008-08-176123

65. Kliche S, Nagel W, Kremmer E, Atzler C, Ege A, Knorr T, et al. Signaling by human herpesvirus 8 kaposin A through direct membrane recruitment of cytohesin-1. Mol Cell (2001) 7:833-43. doi:10.1016/S1097-2765(01) 00227-1

Conflict of Interest Statement: The authors declare that the research was conducted in the absence of any commercial or finical relationships that could be construed as a potential conflict of interest.

Copyright (C) 2017 Grosche, Draßner, Mühl-Zürbes, Kamm, Le-Trilling, Trilling, Steinkasserer and Heilingloh. This is an open-access article distributed under the terms of the Creative Commons Attribution License (CC BY). The use, distribution or reproduction in other forums is permitted, provided the original author(s) or licensor are credited and that the original publication in this journal is cited, in accordance with accepted academic practice. No use, distribution or reproduction is permitted which does not comply with these terms. 